\title{
PENERAPAN METODE STUDI KASUS YIN DALAM PENELITIAN ARSITEKTUR DAN PERILAKU
}

\author{
Ratna Dewi Nur'aini \\ Program Studi Arsitektur, Fakultas Teknik, Universitas Muhammadiyah Jakarta \\ Email: ratnadewina@umj.ac.id
}

\begin{abstract}
ABSTRAK
Studi kasus adalah studi empiris yang menyelidiki fenomena kontemporer dalam konteks kehidupan nyata. Awalnya metode penelitian studi kasus sering digunakan pada bidang ilmu sosial. Namun seiring dengan perkembangan ilmu pengetahuan, metode studi kasus mulai digunakan pada bidang lain. Metode penelitian studi kasus adalah strategi yang tepat untuk digunakan dalam penelitian yang menggunakan pertanyaan penelitian utama "bagaimana" atau "mengapa", diperlukan sedikit waktu untuk mengontrol peristiwa yang dipelajari, dan fokus penelitian adalah fenomena kontemporer. Dalam metode studi kasus, para peneliti fokus pada desain dan implementasi penelitian. Tujuan dari penulisan ini adalah untuk mengkaji metode penelitian studi kasus yang dirumuskan oleh Robert K. Yin dan selanjutnya melihat penerapannya dalam penelitian di bidang arsitektur dan perilaku. Pada penelitian di bidang arsitektur dan perilaku, metode studi kasus Yin ini dapat diaplikasikan walaupun secara parsial dan dapat dikombinasikan dengan metode lainnya. Penelitian bersifat kualitatif dengan kasus yang diamati meliputi kasus tunggal ataupun multi kasus yang pengamatannya berfokus kepada perilaku manusia dan seting lingkungannya.
\end{abstract}

Kata kunci: arsitektur perilaku, kontemporer, studi kasus; studi perilaku, Yin

\begin{abstract}
Case studies are empirical studies that investigate contemporary phenomena in real life contexts. Initially the case study research method was often used in the social science field. But along with the development of science, case study methods began to be used in other fields. The case study research method is the right strategy to use in research that uses the main research questions of "how" or "why", it takes a little time to control the events being studied, and the focus of research is contemporary phenomena. In the case study method, researchers focus on the design and implementation of research. The purpose of this paper is to examine the case study research method formulated by Robert K. Yin and then look at its application in research in architecture and behavior. In research in architecture and behavior, the Yin case study method can be applied even though partially and can be combined with other methods. Qualitative research with observed cases include single or multi-case cases whose observations focus on human behavior and environmental settings.
\end{abstract}

Keywords: behavioral architecture, contemporary, case study, behavioral studies, Yin 
Penerapan Metode Studi... (Ratna/ hal 92-104)

\section{PENDAHULUAN}

Studi kasus merupakan penyelidikan empiris yang menyelidiki fenomena kontemporer dalam konteks kehidupan nyata (Yin, 1981a, 2009). Groat \& Wang (2013) membuat pengertian tentang studi kasus untuk penelitian arsitektur dengan mengubah menjadi penyelidikan empiris yang menyelidiki suatu fenomena atau pengaturan. Dengan menghapus kata kontemporer dan menambahkan pengaturan, pengertian ini mengakomodasi inklusi eksplisit dari fenomena historis dan pengaturan historis. Karakteristik utama dalam studi kasus ini adalah: (1) fokus pada satu atau beberapa kasus, dipelajari dalam konteks kehidupan nyata; (2) menjelaskan hubungan sebab akibat; (3) pengembangan teori dalam fase desain penelitian; (4) tergantung pada berbagai sumber bukti; dan (5) menggeneralisasikan teori.

Pada awalnya metode penelitian studi kasus sering digunakan dalam penelitian dalam bidang ilmu social. Namun seiring perkembangan ilmu, metode studi kasus juga mulai digunakan dalam bidang selain ilmu social.

Tujuan dari penulisan ini adalah untuk mengkaji metode penelitian studi kasus yang dirumuskan oleh Robert K. Yin dan selanjutnya melihat penerapannya dalam penelitian di bidang arsitektur dan perilaku.

Menurut Yin (2009), metode penelitian studi kasus merupakan strategi yang tepat untuk digunakan dalam penelitian yang menggunakan pokok pertanyaan penelitian how atau why, sedikit waktu yang dimiliki peneliti untuk mengontrol peristiwa yang diteliti, dan fokus penelitiannya adalah fenomena kontemporer, untuk melacak peristiwa kontemporer. Pada metode studi kasus, peneliti focus kepada desain dan pelaksanaan penelitian.

Metode penelitian studi kasus dibedakan menjadi 3 (tiga) tipe yaitu: Eksplanatoris, Eksploratoris dan Deskriptif. Beberapa strategi dalam metode penelitian dapat dilihat dalam Tabel 1. Hal penting yang membedakan strategi penelitian ialah identifikasi tipe pertanyaan penelitian yang harus memiliki substansi dan bentuk.

Metode studi kasus intinya hampir sama dengan metode historis hanya ditambahkan dengan observasi dan wawancara secara sistematik. Jenis bukti-bukti dalam metode studi kasus meliputi dokumen, peralatan, wawancara, observasi, dan dalam beberapa situasi dapat terjadi observasi partisipan dan manipulasi informal.

Tabel 1. Strategi Penelitian.

\begin{tabular}{|c|c|c|c|}
\hline Strategi & $\begin{array}{c}\text { Pertanyaan } \\
\text { Penelitian }\end{array}$ & Kontrol & Kontemporer \\
\hline Eksperimen & How, Why & $\mathrm{Ya}$ & $\mathrm{Ya}$ \\
\hline Survei & $\begin{array}{l}\text { Who, What, Where, How } \\
\text { many, How much }\end{array}$ & Tidak & Ya \\
\hline Analisis arsip & $\begin{array}{l}\text { Who, What, Where, How } \\
\text { many, How much }\end{array}$ & Tidak & Ya/Tidak \\
\hline Historis & How, Why & Tidak & Tidak \\
\hline Studi kasus & How, Why & Tidak & Ya \\
\hline
\end{tabular}

Sumber: Yin, 2009

Kelebihan metode studi kasus adalah pertanyaan penelitian how atau why diarahkan pada peristiwa kontemporer sehingga peneliti tidak sedikit atau tidak perlu waktu banyak untuk mengontrolnya.
Perumusan pertanyaan penelitian dengan meninjau kembali bahan-bahan pustaka untuk mencapai tujuan penelitian. 
Pada zaman dahulu beberapa orang mempunyai pendapat yang kurang baik terhadap metode studi kasus dengan alasan metode ini tidak rapi dan mengizinkan adanya bukti yang samar dan bias, sedikit dalam memberikan landasan generalisasi ilmiah, penyelenggaraan lama dengan menghasilkan dokumen yang banyak sehingga akan melelahkan pembacanya. Namun dalam perkembangannya pendapat yang kurang baik tersebut kemudian hilang.

Menurut Schramm (1971), studi kasus hanya mengulangi jenis topic yang aplikatif. Esensinya adalah mencoba menjelaskan keputusan tentang mengapa studi dipilih, bagaimana mengimplementasikannya, dan apakah hasilnya. Sedangkan menurut Yin (1981b), studi kasus adalah suatu inkuiri empiris yang menyelidiki fenomena di dalam konteks kehidupan nyata, batas antara fenomena dan konteks tidak terlihat jelas, dan multi sumber bukti dimanfaatkan.

Studi kasus dapat mencakup juga bukti kuantitatif. Studi kasus hendaknya tidak dikaburkan dengan pengertian penelitian kualitatif (Schwartz \& Jacobs, 1979; Van Maanen et al., 1982). Tipe penelitian kualitatif tidak selalu membuahkan studi kasus, sebaliknya studi kasus tidak selalu terbatas pada kondisi dalam penelitian kualitatif. Studi kasus juga bisa digunakan dalam penelitian evaluasi dengan aplikasi keterkaitan kausal dalam intervensi kehidupan, mendeskripsikan konteks kehidupan di mana intervensi telah terjadi, deskriptif dari studi kasus ilustratif, jurnalistik tentang intervensi, mengeksplorasi situasi di mana intervensi yang dievaluasi tidak memiliki struktur yang jelas.

Pengertian desain penelitian adalah suatu rencana tindakan dari pertanyaan penelitian hingga konklusinya, menentukan ranah generalisasi (Nacmias \& Nachmias, 1976), sebagai blue print penelitian (Philiber et al., 1980), menghindari data yang tidak mengarah pada pertanyaan penelitian.

Aspek kualitas dalam desain penelitian terdiri dari beberapa hal, yaitu (Kidder, 1981):

1) Construct validity, menetapkan ukuran operasional yang benar untuk konsep yang akan diteliti.

2) Internal validity (khusus penelitian eksplanatoris dan kausal), menetapkan hubungan kausal di mana kondisi tertentu diperlihatkan guna mengarahkan kondisi lain.

3) External validity, menetapkan ranah di mana temuan suatu penelitian dapat divisualisasikan.

4) Reliability, pelaksanaan suatu penelitian seperti prosedur pengumpulan data dapat diinterpretasikan dengan hasil yang sama.

Taktik pengujian kualitas studi kasus dan tahapannya dapat dilihat pada Tabel 2.

Tabel 2. Taktik Uji Kualitas Studi Kasus.

\begin{tabular}{|c|c|c|}
\hline UJI & TAKTIK & $\begin{array}{c}\text { TAHAP } \\
\text { PENELITIAN }\end{array}$ \\
\hline Construct validity & $\begin{array}{l}\text { Multi sumber bukti } \\
\text { Rangkaian bukti } \\
\text { Informan meninjau ulang draft laporan }\end{array}$ & $\begin{array}{l}\text { Pengumpulan data } \\
\text { Pengumpulan data } \\
\text { Laporan }\end{array}$ \\
\hline Internal validity & $\begin{array}{l}\text { Pola penjodohan } \\
\text { Penyusunan eksplanasi } \\
\text { Analisis deret waktu }\end{array}$ & $\begin{array}{l}\text { Analisis data } \\
\text { Analisis data } \\
\text { Analisis data }\end{array}$ \\
\hline External validity & Logika replica dalam studi multikasus & Desain penelitian \\
\hline Reliability & $\begin{array}{l}\text { Protokol studi kasus } \\
\text { Kembangkan data dasar }\end{array}$ & $\begin{array}{l}\text { Pengumpulan data } \\
\text { Pengumpulan data }\end{array}$ \\
\hline
\end{tabular}

Sumber: Yin, 2009 
Sedangkan komponen-komponen dalam desain penelitian studi kasus meliputi (Yin, 2009):

1) Pertanyaan penelitian, berpola "how" atau "why"

2) Proposisi, merupakan pernyataan yang merefleksikan isu-isu teoretis yang penting dan akan membimbing peneliti mencari data yang relevan. Proposisi diturunkan dari teori, logika, dan/atau pengetahuan umum yang akan membimbing peneliti untuk tetap focus sehingga tidak akan membahas "semua hal".

3) Unit analisis, berkaitan dengan masalah penentuan apa yang dimaksud dengan "kasus" dalam penelitian yang bersangkutan.

4) Logika (hubungan antara data dan proposisi), menjelaskan tahap analisis data penelitian.

5) Kriteria (interpretasi temuan). Kriteria harus cocok dan berkaitan dengan proposisi, sekaligus dengan pertanyaan penelitian.

Tipe desain dalam studi kasus meliputi kasus tunggal dan multi kasus. Pemilihan kasus tunggal biasanya terjadi pada pengujian kritis teori yang signifikan, kasus ekstrim atau unik, dan penyingkapan kasus itu sendiri. Sedangkan multi kasus digunakan pada temuan yang lebih merangsang dan lebih kuat, banyak sumber untuk diteliti, dan membutuhkan waktu yang ekstra. Terdapat 4 (empat) tipe desain studi kasus yaitu (Yin, 2009): (1) Kasus tunggal holistic; (2) Kasus tunggal embedded; (3) Multi kasus holistic; dan (4) Multi kasus embedded dapat dirumuskan dalam Tabel 3. Sedangkan tipe desain dalam studi kasus ini dapat digambarkan diagramnya pada Gambar 1.

Tabel 3. Tipe Desain Studi Kasus

\begin{tabular}{lcc}
\hline \multicolumn{1}{c}{ ITEM } & KASUS TUNGGAL & MULTI KASUS \\
\hline $\begin{array}{l}\text { Holistic } \\
\text { (unit analisis tunggal) }\end{array}$ & Tipe 1 & Tipe 3 \\
$\begin{array}{l}\text { Embedded } \\
\text { (unit multi analisis) }\end{array}$ & Tipe 2 & Tipe 4 \\
\hline Sumber: Yin, 2009 & &
\end{tabular}

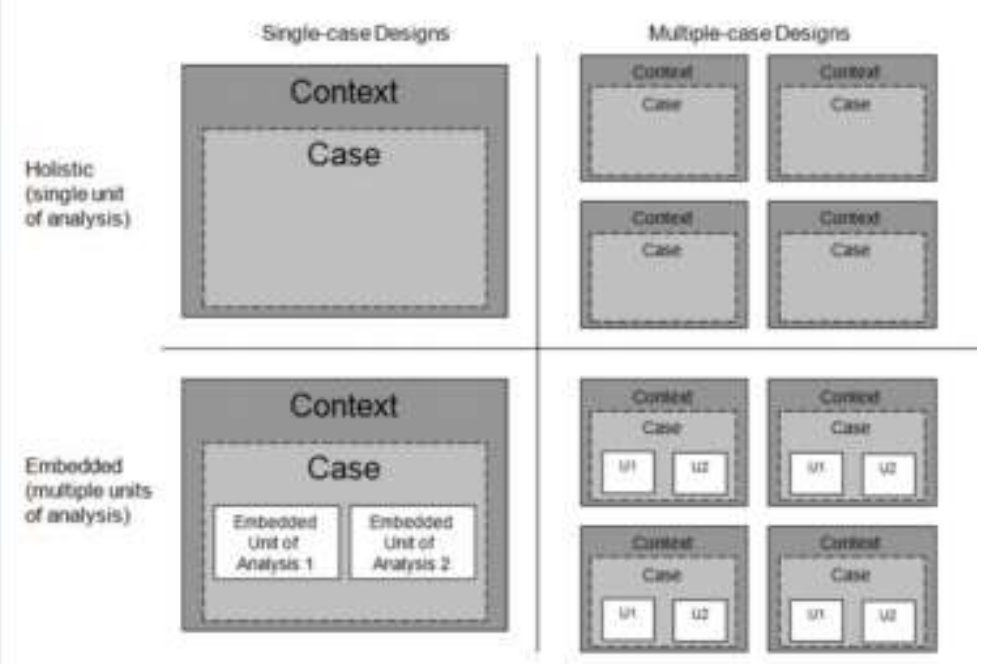

Gambar 1. Diagram Tipe Desain dalam Studi Kasus (Sumber: Yin, 2009). 
Tipe desain multi kasus pada studi kasus ini dilakukan dengan cara kasus 1 diselesaikan dulu baru kemudian beralih pada kasus berikutnya. Cara ini dapat digambarkan dalam diagram Gambar 2.

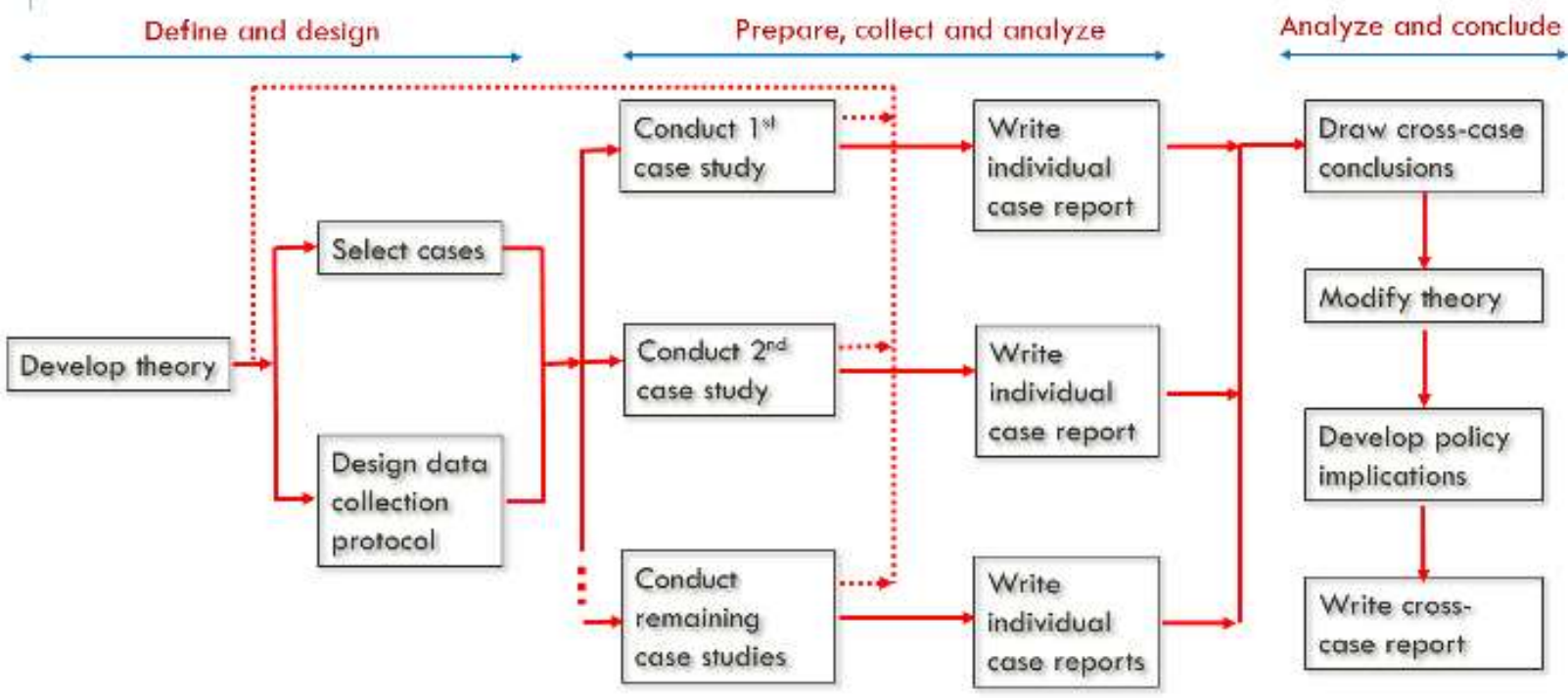

Gambar 2. Diagram Metode Studi Kasus

(Sumber: Yin, 2009)

Dalam suatu penelitian, pokok-pokok keterampilan yang harus dimiliki oleh peneliti adalah mengajukan pertanyaan, mendengarkan, penyesuaian diri dan fleksibel, memegang teguh isu yang akan diteliti, dan mengurangi bias. Selain itu beberapa hal yang perlu diketahui oleh peneliti adalah mengapa penelitian itu dilakukan, bukti apa yang akan dicari, variasi apa yang dapat diantisipasi, dan apa yang menjadi bukti pendukung atau bertentangan dengan proposisi.

Pada saat pengumpulan data, fungsi protocol sangat penting. Protocol lebih dari sekedar instrument, berisi prosedur dan aturan umum yang perlu diikuti, merupakan taktik umum dalam meningkatkan reliabilitas penelitian, membimbing peneliti. Protocol berisi tinjauan umum proyek, prosedur lapangan, pertanyaan, dan petunjuk laporan.

Beberapa teknik pengumpulan data yang dilakukan pada metode studi kasus adalah (Yin, 2009):

1) Dokumentasi: surat, memorandum, pengumuman resmi, agenda, kesimpulan pertemuan, laporan peristiwa tertulis, dokumen administrative, proposal, laporan kemajuan, dokumen intern, penelitian, evaluasi resmi, kliping, artikel media masa. Kegunaannya untuk menverifikasi ejaan, judul, nama yang benar, menambah rincian spesifik, membuat inferensi.

2) Rekaman arsip: komputerisasi, rekaman layanan, rekaman keorganisasian, peta dan bagan karakteristik geografis, daftar nama dan komoditi, data survei (rekaman, sensus), rekaman pribadi (buku harian, kalender, nomor telpon).

3) Wawancara: open-ended, terfokus, terstruktur

4) Observasi langsung: pertemuan, kegiatan, kerja pabrik, ruang kelas. 
Penerapan Metode Studi... (Ratna/ hal 92-104)

Observasi langsung ini memahami konteks maupun fenomena.

5) Observasi partisipan: menjadi penduduk di lingkungan social, mengambil peran fungsional, berperan sebagai anggota organisasi, menjadi pembuat keputusan kunci. Kelebihan menggunakan observasi partisipan ini adalah memperoleh peluang untuk mendapatkan akses dan peluang memanipulasi peristiwa. Sebaliknya kekurangannya adalah kurangnya kemampuan peneliti sebagai pengamat dan cenderung mengikuti fenomena umum.

6) Perangkat fisik (kultural): peralatan teknologi, alat/instrumen, pekerjaan seni. Teknik ini kurang potensial digunakan dalam studi kasus.

Prinsip dalam pengumpulan data adalah menggunakan multi sumber bukti, menciptakan data dasar studi kasus (catatan, dokumen, bahan tabulasi, narasi), dan memelihara rangkaian bukti.

Analisis data terdiri dari pengujian, pengkategorian, pentabulasian, ataupun pengombinasian kembali bukti-bukti untuk menunjuk proposisi awal suatu penelitian. Teknik analisis data menurut Miles \& Huberman (1984) diartikan sebagai:

1) Memasukkan informasi ke dalam daftar,

2) Membuat matriks kategori,

3) Analisis data flowchart,

4) Tabulasi frekuensi peristiwa,

5) Memeriksa tabulasi yang kompleks dan mengkalkulasi angka urutan kedua,

6) Memasukkan informasi ke dalam urutan kronologis.

Bentuk analisis yang dominan dilakukan dalam penelitian studi kasus adalah (Yin, 2009):

1) Perjodohan pola, yang meliputi variable non equivalen sebagai pola (dependent), eksplanasi tandingan sebagai pola (independent), dan pola lebih sederhana.

2) Pembuatan ekspalanasi

3) Analisis deret waktu, yang meliputi deret waktu sederhana, deret waktu kompleks, dan kronologis

Sedangkan analisis yang kurang dominan dilakukan dalam penelitian studi kasus yaitu:

1) Menganalisis unit terjalin, unit kurang dominan dibandingkan kasusnya.

2) Membuat observasi berulang, merupakan analisis deret waktu khusus.

3) Mengerjakan survey kasus, merupakan analisis sekunder lintas kasus.

Yin (2009) membagi jenis laporan penelitian dengan menggunakan metode studi kasus meliputi laporan tertulis dan laporan tidak tertulis (lisan). Laporan tertulis pada kasus tunggal klasik meliputi buku, laporan, artikel jurnal. Sedangkan laporan tertulis pada multi kasus meliputi bab pada masingmasing kasus.

Struktur laporan yang disarankan oleh Yin (2009) pada penelitian studi kasus meliputi:

1) Linear - analytic.

Struktur ini merupakan pendekatan standar untuk membuat laporan penelitian. Urutan sub topiknya mencakup isu atau permasalahan yang diteliti, metode yang digunakan, temuan data yang dikumpulkan dan dianalisis, konklusi serta implikasi dari temuan,

2) Comparative.

Pada struktur komparatif mengulangi studi kasus yang sama sebanyak 2 (dua) kali atau lebih dengan membandingkan alternative deskriptif atau eksplanasi kasus yan 
sama. Tujuan pengulangan tersebut untuk menunjukkan tingkat di mana fakta-fakta berkesesuaian dengan masing-masing model.

3) Chronological. Jenis pendekatan dalam struktur ini adalah urutan kronologis. Urutan bab atau bagian mengikuti tahap permulaan, pertengahan dan akhir dari suatu sejarah kasus. Struktur ini berperan penting dalam pelaksanaan studi kasus eksplanatoris karena urutan kausal harus terjadi secara linear.

4) Theory - building.

Pada struktur ini urutan bab atau bagian mengikuti logika pengembangan teori. Logika tersebut tergantung kepada topic dan teori yang spesifik.

5) Suspense.

Struktur ini berlawanan arah dengan pendekatan analitis. Hasil langsung suatu studi kasus secara paradox disajikan di dalam bab atau bagian pendahuluan. Bagian yang paling menegangkan disajikan pada pengembangan eksplanasi hasilnya dengan alternative penjelasan yang dipertimbangkan di dalam bab atau bagian berikutnya. Jenis struktur ini relevan untuk studi kasus eksplanatoris.

6) Unsequenced

Struktur ini urutan bab atau bagiannya mengasumsikan tidak adanya kepentingan khusus. Struktur ini relevan untuk studi kasus deskriptif. Pada penggunaan struktur yang tidak berurutan ini peneliti perlu memperhatikan uji kelengkapan secara keseluruhan.

Aplikasi struktur laporan pada penelitian studi kasus dapat dilihat pada Tabel 4.

Tabel 4. Aplikasi Struktur Laporan Penelitian Studi Kasus

\begin{tabular}{lccc}
\multicolumn{1}{c}{ Jenis Struktur } & Eksplanatoris & Deskriptif & Eksploratoris \\
\hline 1. Linear-analytic & $\sqrt{ }$ & $\sqrt{ }$ & $\sqrt{ }$ \\
2. Comparative & $\sqrt{ }$ & $\sqrt{ }$ & $\sqrt{ }$ \\
3. Chronological & $\sqrt{ }$ & - & $\sqrt{ }$ \\
4. Theory-building & $\sqrt{ }$ & - & - \\
5. Suspense & $\sqrt{ }$ & $\sqrt{ }$ & - \\
1.Unsequenced & - & &
\end{tabular}

\section{METODE}

Metode yang digunakan pada kajian ini adalah studi literatur/referensi, tujuannya untuk menggali pengetahuan tentang metode studi kasus yang dirumuskan oleh Robert K Yin. Setelah itu mengkaji beberapa penelitian yang berhubungan dengan arsitektur dan perilaku yang menggunakan metode studi kasus untuk diidentifikasi kesesuaian dengan metode studi kasus yang telah dirumuskan oleh Yin. Dari beberapa penelitian yang dikaji akan ditarik kesimpulan bagaimana penerapan metode studi kasus yang telah dirumuskan oleh Yin dalam pelaksanaan penelitian di bidang arsitektur dan perilaku. 


\section{HASIL DAN PEMBAHASAN}

Pada bagian ini akan dibahas beberapa contoh penelitian yang berhubungan dengan arsitektur dan perilaku yang mengacu kepada metode studi kasus. Beberapa contoh penelitian ini adalah sebagai berikut.

Territorial Behaviour and The Built Environment, The Case of Arab-Muslim Towns, Saudi Arabia (Al-Said, 1992). Penelitian ini bertujuan mengeksplorasi efek perilaku teritorial manusia dalam membentuk lingkungan yang dibangun Arab-Muslim di masa lalu, sekarang, dan masa depan, serta menetapkan kesinambungan antara lingkungan tradisional dan kontemporer Arab-Muslim yang dibangun, kasus lingkungan Arab Saudi. Metode yang digunakan pada penelitian ini dengan tahapan sebagai berikut:

a. Critical review terhadap theoretical knowledge yang ada tentang fenomena perilaku teritorial manusia untuk merasionalisasikan dan mencocokkan dengan sifat dinamis lingkungan yang dibangun ArabMuslim.

b. Mengamati teritorial manusia sebagai perilaku spasial dan menelusuri ke akarnya dalam ilmu perilaku, terutama Psikologi dan Sosiologi, dan desain sebagai seni tata ruang. Fase perilaku teritorial manusia (Allocation, Attainment, Maintenance, dan Abandonment) secara paralel dengan kasus/tahapan desain ruang lingkungan yang dibangun (Nesting, Stringing, dan Clustering)

c. Review historical knowledge tentang lingkungan Arab-Muslim tradisional, dan menyelidiki asal dan proses teritorial Arab-Muslim dan pengaruhnya pada lingkungan.

d. Mengamati sistem kepemilikan hukum Islam (syariah) dan membangun hak guna lingkungan sebagai parameter untuk mendefinisikan jenis teritorial lingkungan tradisional Arab-Muslim (Public and jurisdictional, semi public, semi private, and private and personal space). Perbedaan ini memverifikasi kepercayaan umum bahwa lingkungan yang dibangun Arab-Muslim adalah hasil dari pelanggaran batas terus-menerus oleh penduduk pada ruang publik yang tersedia.

e. Penelitian ini tidak hanya bergantung pada tinjauan kritik teoretis dan historis, tetapi juga tergantung pada analisis foto udara lingkungan buatan Saudi yang tertanggal 1935 hingga sekarang. Analisis ini menyisakan sedikit ruang untuk spekulasi tentang proses di mana lingkungan yang dibangun Saudi dibentuk dan diubah.

f. Penelitian ini berakhir dengan gagasan yang mungkin yang dapat disarankan dengan cara membangun kembali rasa kontinuitas antara masa lalu, sekarang, dan efek masa depan perilaku teritorial manusia terhadap lingkungan yang dibangun ArabMuslim dalam kasus kota-kota Arab Saudi.

g. Hal ini dicapai melalui pengenalan kembali konsep Fina tradisional ke dalam lingkungan binaan kontemporer sebagai sarana untuk melepaskan karakteristik transformasi yang terlupakan pada skala jalan. Rilis ini dilihat sebagai cara mendaur ulang ruang kota kontemporer dan diatur oleh perancang, otoritas lokal lingkungan, dan kotamadya kota. 
h. Penelitian ini merupakan titik balik dalam pemahaman lingkungan dibangun Arab-Muslim, memperkenalkan faktor perilaku teritorial manusia yang mempengaruhi pembentukan dan transformasi lingkungan ArabMuslim yang dibangun.

A study of the Effects of Computer Use on the Social Interaction Behaviour of Malaysian Children in the Pre-School Classroom (Razali, 2006). Penelitian ini bertujuan mempelajari interaksi terhadap teman pada penggunaan komputer, mempelajari interaksi guru dengan anak-anak dan menganalisis dampak interaksi tersebut pada perilaku sosial anak-anak, mengeksplorasi keyakinan, pandangan, dan pengetahuan guru tentang penggunaan komputer pada empat pra-sekolah di Malaysia. Metode yang digunakan pada penelitian ini dengan tahapan sebagai berikut:

a. Pendekatan kualitatif, desain studi kasus untuk pengumpulan data.

b. Perspektif dan paradigma yang mendukung penelitian dibuat transparan.

c. Tiga pendekatan umum untuk penyelidikan: interpretatif, antropologi sosial dan penelitian sosial kolaboratif.

d. Penelitian kualitatif menggunakan pendekatan studi kasus ganda berdasarkan konstruktivisme.

e. Data diperoleh terutama melalui non-peserta observasi, wawancara dengan kepala sekolah, guru dan anak-anak dan dokumentasi.

f. Fokus: deskripsi mendalam anakanak dalam menggunakan komputer pada ruang kelas pra-sekolah di Malaysia.

g. Sifat penelitian: eksplanatori, eksploratif dan deskriptif.

h. Pertanyaan penelitian 'how' dan 'why' adalah pertanyaan kunci ketika mengidentifikasi posisi penggunaan komputer di kelas pra-sekolah Malaysia.

i. Pertanyaannya mengamati peristiwa kontemporer di mana peneliti memiliki sedikit atau tanpa kendali.

j. Studi ini bersifat partikularistik karena berfokus pada bagaimana siswa dan guru menggunakan komputer dalam seting ruang prasekolah.

k. Studi kasus deskriptif karena tujuan dari penelitian ini adalah untuk lebih memahami proses penggunaan komputer di kelas anak usia dini.

1. Penelitian bersifat heuristik karena bergantung pada interpretasi dari data yang dikumpulkan.

m. Studi kasus ganda dimulai dari satu kasus dan kemudian diperluas menjadi dua atau lebih. Kasus yang ditambahkan untuk meningkatkan generalisasi penelitian. Kasus tambahan mungkin melibatkan keragaman untuk rentang pengamatan yang lebih luas.

n. Multiple cases (4 cases) diterapkan dengan tujuan memperluas kasus.

o. Informasi kasus I (Pra-sekolah A) digunakan sebagai landasan untuk Kasus 2, Kasus 3 dan Kasus 4. Setiap kasus dianalisis secara individual dan peneliti mengidentifikasi masalah yang sama atau berbeda atau baru muncul. Peneliti menganalisis mengapa kasus-kasus tertentu menghasilkan hasil tertentu, sedangkan kasus lain, menghasilkan hasil yang kontras.

Multi kasus pada penelitian ini dapat digambarkan dalam kerangka teori pada Gambar 3 berikut ini: 


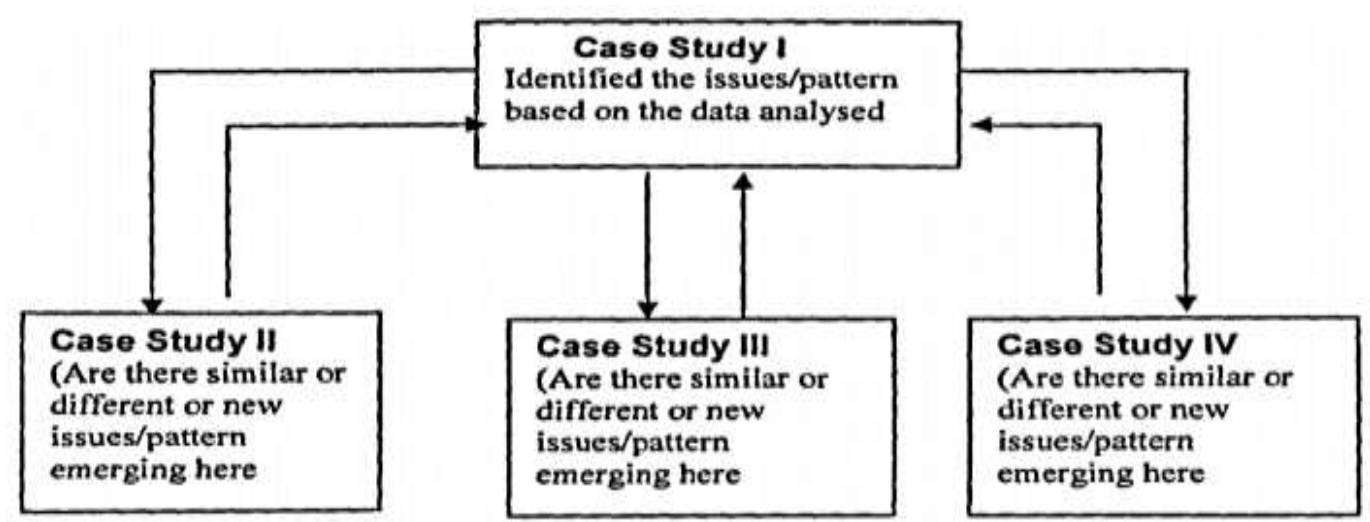

Gambar 3. Kerangka Teori Multi Kasus

(Sumber: Razali, 2006)

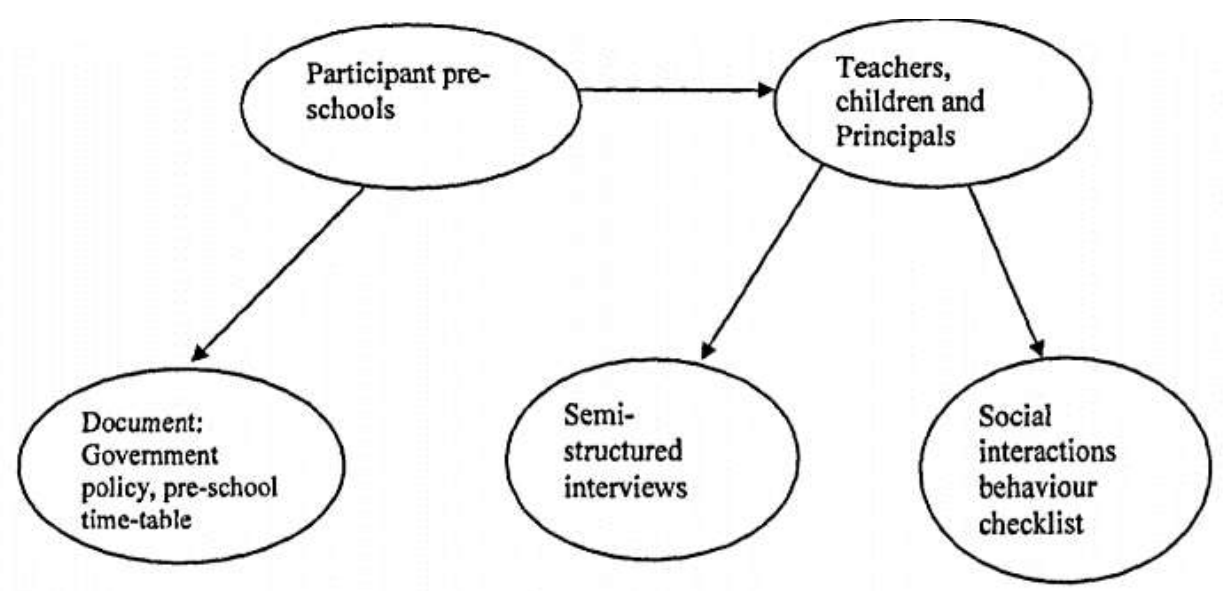

Gambar 4. Instrumen untuk pengumpulan data

(Sumber: Razali, 2006)

Instrumen yang digunakan untuk pengumpulan data dalam penelitian ini dijelaskan dalam Gambar 4. Teknik pengumpulan data utama adalah observasi dengan pengamatan sistematis (terstruktur) di mana mengamati perilaku individu dalam schedule of categories. Setiap orang diamati dalam jangka waktu yang ditentukan dengan rules yang sama.

\section{Ruang Sosial Anak di Kampung Padat Kota} Kasus Kampung Ngampilan Yogyakarta (Sativa, 2018). Tujuan dari penelitian ini adalah menggali konsep ruang sosial anak di kampung kota yang memiliki tekanan lingkungan tinggi, agar bisa digunakan sebagai acuan perencanaan dan pengembangan kampung kota ke depan.

Penelitian ini dalam bidang hubungan antara lingkungan dan perilaku manusia. Penelitian yang berfokus pada ruang berinteraksi anak/ruang sosial anak di Kampung Ngampilan ini dilakukan secara eksploratif di lapangan, dengan menggunakan konstruksi/ kisi-kisi teoretik tentang hubungan antara lingkungan dan perilaku manusia. Metode yang digunakan dalam penelitian ini adalah rasionalistik, dan menggali data secara eksploratif di lapangan. Sebagai kasus, dipilih Kampung Ngampilan Yogyakarta, sebagai kampung yang densitas penduduk dan bangunannya tinggi, rerata ekonomi penduduknya 
termasuk rendah, dan terletak di bantaran sungai dengan kondisi geografis yang khas.

Teknik pengumpulan data dengan cara observasi (casual, sistematik, dan partisipatif), wawancara (terhadap anak, orang tua, dan tokoh kampung), placecentered map untuk menggali pola perilaku pada suatu ruang, physical traces (jejak fisik), dan triangulasi data untuk memperoleh derajat keabsahan informasi yang lebih baik.

Pada setiap kasus, data dianalisis secara induktif dengan menggunakan kerangka teoretik sinomorfi, untuk menemukan bagaimana seting fisik ruang dan pola perilaku yang terjadi. Selanjutnya dirumuskan hasil akhir analisis hubungan antara manusia, seting fisik dan waktu, untuk menemukan atribut tiap ruang (skala mikro). Tahap berikutnya, temuan atribut tiap ruang saling didialogkan, dengan hasil akhir berupa atribut ruang sosial anak skala meso/kampung, yang kemudian menjadi acuan perumusan konsep ruang anak sosial di Kampung Ngampilan Yogyakarta. Kerangka analisis ini dapat dilihat pada Gambar 5 berikut ini.

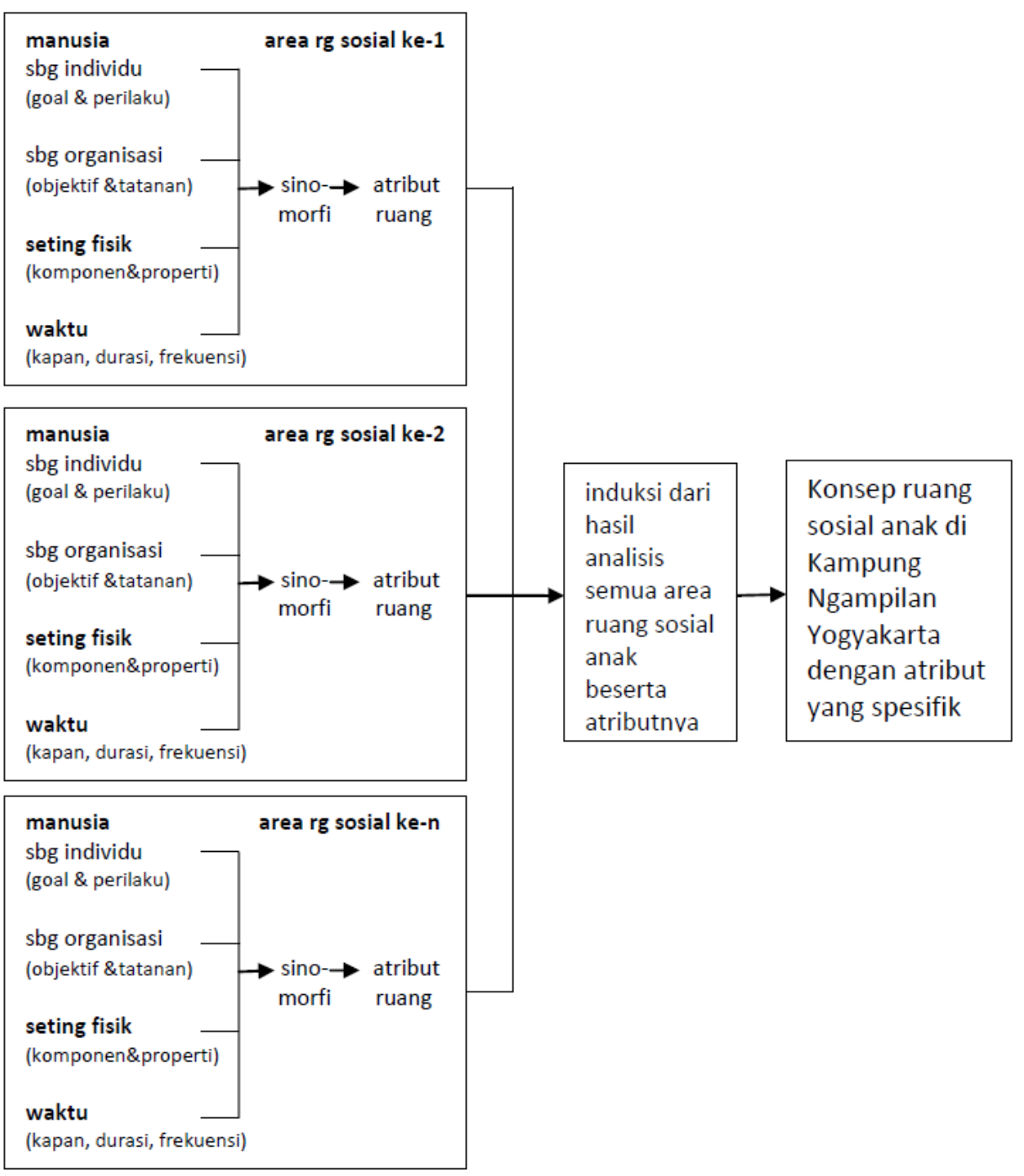

Gambar 5. Kerangka analisis induktif data penelitian (Sumber: Sativa, 2018) 
Tabel 5. Penelitian tentang Arsitektur dan Perilaku

\begin{tabular}{|c|c|c|}
\hline Peneliti & Fokus & Penerapan metode studi kasus \\
\hline $\begin{array}{l}\text { Fahad A.M. Al-Said } \\
1992\end{array}$ & $\begin{array}{l}\text { Mengeksplorasi efek perilaku } \\
\text { teritorial manusia dalam } \\
\text { membentuk lingkungan pada } \\
\text { masa lalu, sekarang, dan masa } \\
\text { depan. }\end{array}$ & $\begin{array}{l}\text { Pertanyaan penelitian how dan why. } \\
\text { Kritik teoritis dan historis. } \\
\text { Pengamatan perilaku, teritori, system } \\
\text { kepemilikan, sejarah, dan transformasi } \\
\text { lingkungan. }\end{array}$ \\
\hline $\begin{array}{l}\text { Mahani Razali } \\
2006\end{array}$ & $\begin{array}{l}\text { Menganalisis dampak interaksi } \\
\text { anak terhadap teman, interaksi } \\
\text { guru dengan anak terhadap } \\
\text { perilaku sosial anak pada } \\
\text { penggunaan komputer di pra- } \\
\text { sekolah. }\end{array}$ & $\begin{array}{l}\text { Pertanyaan penelitian how dan why } \\
\text { Kualitatif, multi kasus, konstruktivisme. } \\
\text { Observasi, wawancara, dokumentasi. } \\
\text { Bersifat ekspanatori, eksploratif dan deskriptif. } \\
\text { Pendekatan interpretatif, antropologi sosial dan } \\
\text { sosial kolaboratif. } \\
\text { Pengamatan perilaku. }\end{array}$ \\
\hline $\begin{array}{l}\text { Sativa } \\
2018\end{array}$ & $\begin{array}{l}\text { Menggali konsep ruang sosial } \\
\text { anak di kampung kota yang } \\
\text { memiliki tekanan lingkungan } \\
\text { tinggi. }\end{array}$ & $\begin{array}{l}\text { Pertanyaan penelitian how dan why. } \\
\text { Rasionalistik eksploratif. } \\
\text { Kasus tunggal dan multi unit amatan } \\
\text { Observasi, wawancara, place-centered map, } \\
\text { physical traces, dan triangulasi data. } \\
\text { Pengamatan seting dan perilaku. } \\
\text { Analisis induktif. }\end{array}$ \\
\hline
\end{tabular}

Built Environment, The Case Of ArabMuslim Towns, Saudi Arabia. United Kingdom: Mackintosh School of Architecture, University of Glasgow.

Metode studi kasus Robert K. Yin secara luas dapat digunakan dalam penelitian di bidang social ataupun bidang lainnya. Karakteristik utama dalam studi kasus ini adalah berfokus pada kasus tunggal atau multi kasus yang dipelajari dalam kehidupan nyata, dapat menjelaskan hubungan sebab akibat dengan mengembangkan teori dalam fase desain penelitian yang bergantung pada sumber bukti, dan menghasilkan generalisasi teori.

Pada penelitian bidang arsitektur dan perilaku, metode studi kasus Yin dapat diaplikasikan walaupun secara parsial dan dapat dikombinasikan dengan metode lainnya. Penelitian bersifat kualitatif dengan kasus yang diamati meliputi kasus tunggal ataupun multi kasus yang pengamatannya berfokus kepada perilaku manusia dan seting lingkungannya.

\section{DAFTAR RUJUKAN}

Al-Said, F. (1992). Territorial Behaviour And The
Groat, L. N., \& Wang, D. (2013). Architectural Research Methods (2nd ed.). New Jersey: John Wiley \& Sons, Inc.

Kidder, L. (1981). Research Methods on Social Relations (4th ed.). New York: Holt, Rinehart \& Winston.

Miles, M. B., \& Huberman, A. M. (1984). Analyzing Qualitative Data: A Source Book for New Methods. Beverly Hills: Sage Publications, Inc.

Nacmias, D., \& Nachmias, C. (1976). Research Methods in The Social Sciences. New York: St. Martin's.

Philiber, S. G. Samsloss, G. (1980). Social Research: Guides to a Decision-Making Process. Itasca, IL: Peacock.

Razali, M. (2006). A Study of The Effects of Computer Use on The Social Interaction Behaviour of Malaysian Children in The Pre-School Classroom. University of Glasgow.

Sativa. (2018). Ruang Sosial Anak di Kampung Padat Kota. Universitas Gadjah Mada. 
Schramm, W. (1971). Notes on Case Studies of Instructional Media Projects. Working paper for academy for Educational Development. Washington DC.

Schwartz, H., \& Jacobs, J. (1979). Qualitative Sociology: A Method to The Madness. New York: Free Press.

Van Maanen, J. ... Faulkner, R. R. (1982). Varieties of Qualitative Research. Beverly Hills: Sage Publication.

Yin, R. K. (1981a). The Case Study as a Serious Research Strategy. Knowledge: Creation, Diffusion, Utilization, 3(1), 97-114. https://doi.org/10.1177/107554708100300 106

Yin, R. K. (1981b). The Case Study Crisis: Some Answers. Administrative Science Quarterly (ed. 26 Mar).

Yin, R. K. (2009). Case Study Research Design and Methods (4th ed. Vo). Sage Publication. 